\title{
A EVOLUÇÃO DOS POLÍMEROS NA INDÚSTRIA AUTOMOBILISTICA
}

\author{
Joecy de Almeida Campos Filho - joecy.filho@alunos.unis.edu.br \\ Lays Fernandes Lanes de Sousa - lays.sousa@alunos.unis.edu.br \\ Marcos Jose Duarte - marcos.duarte@alunos.unis.edu.br \\ Orientador: Márcia Marazo Pinto - marcia.pinto@professor.unis.edu.br \\ Zarur de Oliveira Silvano - zarurs@yahoo.com.br
}

\begin{abstract}
Resumo
Este estudo analisa as vantagens da utilização dos materiais poliméricos em relação aos materiais que eram tradicionalmente utilizados na fabricação dos veículos.Entre algumas das vantagens encontradas, estão, redução do peso, redução da emissão de $\mathrm{CO} 2$ e aumento da resistência a corrosão. A partir do anode1991,oplásticopassouaserumtipomaterial

emdestaquesendoumdosmaisusadosnaindústriaautomotiva.Gradativamente, com a evolução da tecnologia e dos estudos sobre os polímeros e sua relação com os automóveis, o trabalho tem como objetivo central explorar a aplicação dos mesmos na indústria automotiva brasileira. Inicialmente é apresentada a evolução dos materiais poliméricos, fabricação e suas propriedades. Por fim será exposto o crescimento desse material na indústria automobilística brasileira em épocas diferentes. O artigo apresenta dados informativos através de gráficos e quadros comparativos.
\end{abstract}

Palavras-chave

polímeros, automóveis, tecnologia

\section{INTRODUÇÃO}

Os seres humanos estão em uma constante evolução, sempre procurando 
apresentar diversas maneiras para melhorar suas atividades primordiais de sobrevivência e bem estar, logo, as indústrias automobilísticas com o passar dos anos foram efetuando mudanças de suas matérias convencionais por plástico, atraídas em especial pelas crises do petróleo nos anos de 1973 e 1979. A maior parte das modificações tecnológicas deve se a aparição dos polímeros como material alternativo.

Neste cenário, é possível enxergar contínuos e inúmeros avanços da tecnologia e estudos científicos em diversos setores, sendo eles: da comunicação, da alimentação da medicina, do transporte, entre outras. A maior parte das modificações ocorridas até os dias atuais se deve à disponibilidade de materiais adequados. Podem-se destacar os polímeros, utilizado principalmente em áreas relevantes da economia como em empresas e setores da saúde.

A indústria de polímeros no Brasil passou a existir na década de 70 , criada por três polos petroquímicos. Em um momento anterior, existiam unidades isoladas fabricando um outro exemplo de polímero, todavia sem uma grande representatividade no PIB brasileiro. Os polos foram criados a partir do padrão de substituição de importação. Para aperfeiçoar o entendimento, este modelo fez com que os polos atuassem da mesma forma que o governo fez com o setor cafeeiro no Brasil, naquele tempo o presidente Getúlio Vargas, sendo o mesmo que deu início ao uso do modelo.

O procedimento de privatização das indústrias que se sucedeu na década de 90 , associado à queda notável nas alíquotas de importação dos produtos poliméricos, modificou de modo completo o perfil da indústria dos polímeros, onde foram vistas junções de empresas, ausência de produtoras, perda de sócios internacionais, e também aquisições dos participantes ativos existentes nas multinacionais estrangeiras que tem uma grande expressão mundialmente. Estas multinacionais, até então, tinham uma certa dificuldade de se tornarem estáveis no país por meio de subsidiárias, autônomas de controle governamental brasileiro, ou até mesmo ter acesso exclusivo às matrizes de fornecimento de matérias primas.

O novo modelo concebido devido aos fatores citados, tem como fundamentação marcante as indústrias mono produtoras, sem economia de escopo que se altera por meio do fortalecimento de grupos grandes em expansão, como a Braskem que se tornou uma grande produtora de polímeros no país, com um enorme portfólio de mercadorias e seu caso mostra uma saída 
para a concorrência das empresas nesta indústria, em meio a aproximação dos mercados financeiros dos países.

Atualmente, essa empresa tem uma produção anual que gira em torno de 4 milhões de toneladas de resina e é responsável pelo municiamento total do mercado no Brasil de commodities poliméricas. Seus movimentos correspondem aproximadamente $1,5 \%$ do PIB do país.

Através das pesquisas efetuadas, este trabalho tem como objetivo mostrar o crescimento do uso dos polímeros na indústriaautomobilística brasileira.

\section{REVISÃO DE LITERATURA}

A metalização dos materiais poliméricos envolve a deposição de filmes metálicos sobre um substrato polimérico e tem fins decorativos e funcionais. $A$ função desses filmes é conferir propriedades não naturais ao polímero, como refletividade, condutividade, etc. (Gomes,2016). A indústria automotiva usa a metalização dos polímeros como alternativa, reduzindo o peso dos veículos com o uso de polímeros ao invés de materiais metálicos (Deyna,2015).

Os materiais polímeros são caracterizados entre si de acordo com seu grau de diferenciação, equivalência de produção, nível de consumo de energia e valor agregado.

Segundo Callister (2016) dependendo da estrutura química, ou seja, do tamanho médio dos poros de cada cadeia e do tipo de ligação covalente, os polímeros podem ser divididos em três categorias: fibra, borracha (ou elastômero) e plástico.

De acordo com o site "Plástico Virtual" (2016), os principais métodos de fabricação de peças automotivas feitas com materiais poliméricos são a moldagem por injeção; moldagem por sopro; termo formagem; extrusão. A moldagem por injeção é o processo mais importante da produção de polímeros, e também o procedimento mais aplicado na fabricação de peças automotivas. A moldagem por sopro é um processo de fabricação extremamente importante, direcionado à produção de artigos ocos ou corpos ocos abertos de um lado. Na primeira etapa da produção por moldagem por sopro, uma pré-forma é produzida por extrusão ou moldagem por injeção. Na segunda etapa, a peça é moldada pela pressão do ar produzida, expandindo o material plástico até 
chegar as paredes internas do molde.

Segundo Callister (2016) Muitos polímeros são compostos orgânicos cujas propriedades químicas são baseadas em carbono, hidrogênio e outros elementos não metálicos.

Polímeros para usos gerais (commodities): grande escala de produção, baixo valor agregado, grande versatilidade, grande consumo.

\subsection{FABRICAÇÃO DOS POLÍMEROS}

De acordo com a ABIPLAST (2015), nos anos de 1970 e 1980 os materiais poliméricos tiveram uma crescente em seus avanços tecnológicos. Proporcionado devido à baixa densidade,resistência mecânica, flexibilidade eisolação, tais materiais começaram a substituir os metais na engenharia e na indústria automotiva. De 1974 a 1988, o uso dos polímeros em automóveis teve um aumento de $11 \%$.

Segundo Abiplast (2016), por questões econômicas e principalmente técnicas, os plásticos e seus derivados tornaram-se um dos materiais mais utilizados na indústria automotiva nos últimos anos. Em primeiro lugar, os polímeros são classificados de acordo com suas características econômicas e técnicas.

O processamento dos polímeros é realizado em altas temperaturas para derretê-lo.Exigindo assim um vasto conhecimento com relação a matéria-prima e seu comportamento sob fluxo, suas propriedades de solidificação, relacionando as condições de processo e as propriedades finais do material.

Normalmente o polímero é um componente contínuo, encarregado pela mudança de uma força sofrida para outro elemento descontínuo que oferece a resistência ao esforço. Portanto a matriz polimérica é o suporte primordial que comanda os atributos mecânicos do material.

Estão sendo desenvolvidos para utilização nas empresas automobilísticas, novos compósitos que vão fornece vantagens ambientais e sociais. Os mesmos são fabricados com matriz polimérica e fibras de madeira.

Foi constatado que materiais diferentes, com propriedades diferentes, podem atender a vários tipos de aplicações utilizando processamento de plásticos convencionais como injeção, compressão e extrusão.

Os compósitos podem apresentar a coloração escura, isso é um aspecto 
das fibras agregadas ao polímero e que desacompanhada, a tendência é degradar com rapidez quando exposto à luz solar e a microrganismos.

\subsubsection{Especialidades dos Polímeros}

O quadro 1 apresenta características e o efeito sobre o desempenho dos materiais compostos por polímeros:

\begin{tabular}{|c|c|c|}
\hline Commodities & Quasi-commodities & Alto desempenho \\
\hline $\begin{array}{c}\text { Resistência a temperatura e } \\
\text { dureza } \\
\text { Baixo custo } \\
\text { Excelente resistência química } \\
\text { Absorção de umidade } \\
\text { tendendo a zero } \\
\text { Muito boas } \\
\text { propriedades elétricas } \\
\text { Baixo coeficiente de fricção }\end{array}$ & $\begin{array}{c}\text { Médio custo } \\
\text { Resistência a temperatura e } \\
\text { a dureza } \\
\text { Boa resistência Química } \\
\text { Boas propriedades } \\
\text { relacionadas ao suporte a } \\
\text { desgaste } \\
\text { Dificuldade de adesão } \\
\text { Baixo coeficiente de fricção }\end{array}$ & $\begin{array}{l}\text { Alto custo } \\
\text { Baixo coeficiente de fricção } \\
\text { Excelente resistência química } \\
\text { Resistência a temperatura }\end{array}$ \\
\hline
\end{tabular}

Fonte: Autoria própria com base em Canevarollo (2002).

Dentre as características dos materiais poliméricos, vale ressaltar que embora possuam sensibilidade mecânica, resistência às intempéries, resistência à oxidação, resistência ao calor, resistência aos raios ultravioleta e outras propriedades. Para mostrar as semelhanças entre as propriedades dos materiais poliméricos e aquelas que podem ser exigidas pelos automóveis, algumas propriedades específicas são descritas a seguir, que são o objetivo deste artigo.

\section{Propriedades Mecânicas}

Segundo Callister (2016), as propriedades dos polímeros e de muitos materiais metálicos são especificadas por parâmetros como módulo de elasticidade, limite de resistência à tração e resistência ao impacto e à fadiga.

\section{Propriedades térmicas}

Segundo Dalmolin (2016) polímeros têm baixa condutividade térmica, degradação térmica e cisão da cadeia ocorrem quando expostos ao 
superaquecimento, o que reduz muito a massa molar e aumenta significativamente a liberação de gases ou vapores químicos.

\section{Propriedades ópticas}

Segundo Callister (2016), dentre as principais propriedades ópticas dos polímeros, está a transparência exibida pelos polímeros amorfos ou pouco cristalinos. Essa característica é demonstrada pela relação entre as extensões de luz que passam pelo material e aquelas que colidem perpendicularmente com as superfícies, de até $92 \%$ para o plástico comum.

O material polimérico cristalino torna-se translúcido, em alguns casos especiais até opaco.

Quevedo (2016), a facilidade de manuseio desse tipo de material levou as indústrias a utilizá-lo em seus processos. Isso gera uma melhoria tecnológica, econômica e ecológica em termos de facilidade de descarte. Os polímeros podem ser divididos de acordo com vários critérios, sendo o principal deles: polímeros naturais e polímeros artificiais.

\section{Polímeros naturais}

Segundo Fogaça (2017), são aqueles que estão nos organismos animais e vegetais e que já são utilizados há alguns milhares de anos pelo ser humano. Essas macromoléculas são chamadas de biomoléculas ou moléculas da vida o motivo, são essenciais para processos que mantêm a vida. Eles juntos compõem três classes: carboidratos, lipídios e proteínas.

\section{Polímeros sintéticos}

Segundo Quevedo (2013), esses tipos de polímeros começaram a ser produzidos em laboratório com o intuito de imitar os polímeros naturais. $\mathrm{O}$ primeiro polímero desse topo de importância comercial foi o celuloide, produzido pela primeira vez em 1864, usado principalmente para a produção de bolas de bilhar, já que eram feitas em marfim e o preço do mesmo estava muito elevado na época.

Os cientistas começaram a partir do celuloide a descobrir mais e mais polímeros sintéticos, sendo que um grande avanço ocorreu ao se descobrir a baquelite por meio de moléculas simples (fenol e formaldeído), no ano de 1909. Vários tipos de fibras têxteis e plásticos são polímeros artificiais. Eles se tornaram tão comuns em nosso dia a dia que se tornou praticamente impossível 
passar um dia sequer sem ter contato com algum.

As inovações tecnológicas poliméricas tendo em vista a indústria automobilística têm como foco alguns executores de aprimoração como por exemplo: facilitar e baratear o preço da extração da matéria base (matéria prima), melhorar e qualificar sua produção, elevar a resistência do material em relação aos impactos, diminuir o efeito de intempéries em longo período no plástico, deixando o mesmo mais maleável e flexível, tornar acessível a todos a tecnologia dos polímeros, abastecer a necessidade de versatilidade do produto que o mercado requer.

\section{METODOLOGIA}

Este trabalho apresenta uma pesquisa descritiva, baseadas em fontes bibliográficas obtidas no google books,googleacadêmico e em endereçoseletrênicos da web scielo eabiplast. O estudo mostra exemplos e especificações pontuais sobre as propriedades, utilizações e evolução dos polímeros no mercado automotivo.

Foi realizada uma pesquisa de levantamento qualitativo, onde buscou comprovar através de um quadro com baseCallister (2002), feito no softerexcel (2019),as vantagens e desvantagens de se utilizar os polímeros na indústria automobilística.

O artigo apresenta um gráfico mostrando a evolução dos polímeros e a integração dos veículos automotores ao longo dos anos.

Segundo Tatiana Freitas - Folha de São Paulo (2013), atualmente com um percentual maior de plástico em sua composição, os veículos tem uma considerável queda no volume, com isso um menor consumo de combustível, contribuindo assim para o meio ambiente.

\section{RESULTADOS E DISCUSSÕES}

\subsection{A indústria automobilística e os polímeros}

Segundo Hemais (2003), os materiais poliméricos apresentam alto índice de confiabilidade e muitas vantagens em relação aos materiais mais tradicionais que os estão substituindo, como aço, alumínio, madeira, ferro fundido e até o próprio ferro. vidro. Os materiais poliméricos, além de 
permitirem maior flexibilidade de design e custo-benefício na sua fabricação, possuem baixa densidade que, quando utilizados na engenharia automotiva, permite redução de peso e, consequentemente, menor desgaste dos carros.

Um estudo da APME (Associação de Produtores de Plásticos na Europa) mostra que a substituição de vários materiais por cerca de cem quilos de plástico em um carro de uma tonelada economizará 7,5\% de combustível. Para cerca de 100 quilos de peças plásticas utilizadas em um veículo, não são consumidos de 200 a 300 quilos de outros materiais, o que se refletirá em seu peso final.

Portanto, um veículo com a vida sua útil de 200 mil quilômetros, poderá economizar, um valor aproximado de, 1000 litros de combustível por conta da a utilização dos polímeros. O quadro a seguir demostra um conjunto mais detalhado das mais importantes vantagens e desvantagens identificadas na utilização dos polímeros como parte compositora de um automóvel.

Quadro1- Vantagens e desvantagens da utilização de polímeros pela indústria automobilística em detrimento a outros materiais.

\begin{tabular}{|c|c|}
\hline Vantagens & Desvantagens \\
\hline Redução do peso & $\begin{array}{c}\text { Deterioração por Ação térmica e } \\
\text { ambiental }\end{array}$ \\
\hline Redução da emissão de CO2 & Inflamabilidade \\
\hline Redução de custos & Baixa resistência ao impacto \\
\hline Redução do tempo de produção & Deformação permanente elevada \\
\hline Menores investimentos em manufatura & $\begin{array}{c}\text { Dificuldade de adesão de película e } \\
\text { tinta }\end{array}$ \\
\hline Aumento da resistência a corrosão & Facilidade de machas permanentes \\
\hline Possibilidade de designs mais modernos & Baixa estabilidade dimensional \\
\hline Formatos mais complexos & \\
\hline Excelente processabilidade & \\
\hline Veículos mais silenciosos & \\
\hline Melhor uso dos espaços & \\
\hline
\end{tabular}

Fonte: Autoria própria com base emCallister (2002)

O quadro 2 está mostrando algumas vantagens e desvantagens da utilização de polímeros na indústria automotiva, essas vantagens sendo incluídas ao mercado vem trazendo cada vez mais átona as vantagens de se utilizar os polímeros nos automóveis, acarretando assim benefícios significativos para o meio ambiente e para o cliente final. 
Segundo a Associação Brasileira das locadoras de automóveis o Brasil em 2011 foi o quarto maior consumidor de veículos no mundo, com 3,63 milhões de emplacamentos ficando atrás apenas de Estados Unidos, China e Japão.

Figura 1 - Evolução total da frota na década de (1957-2015)

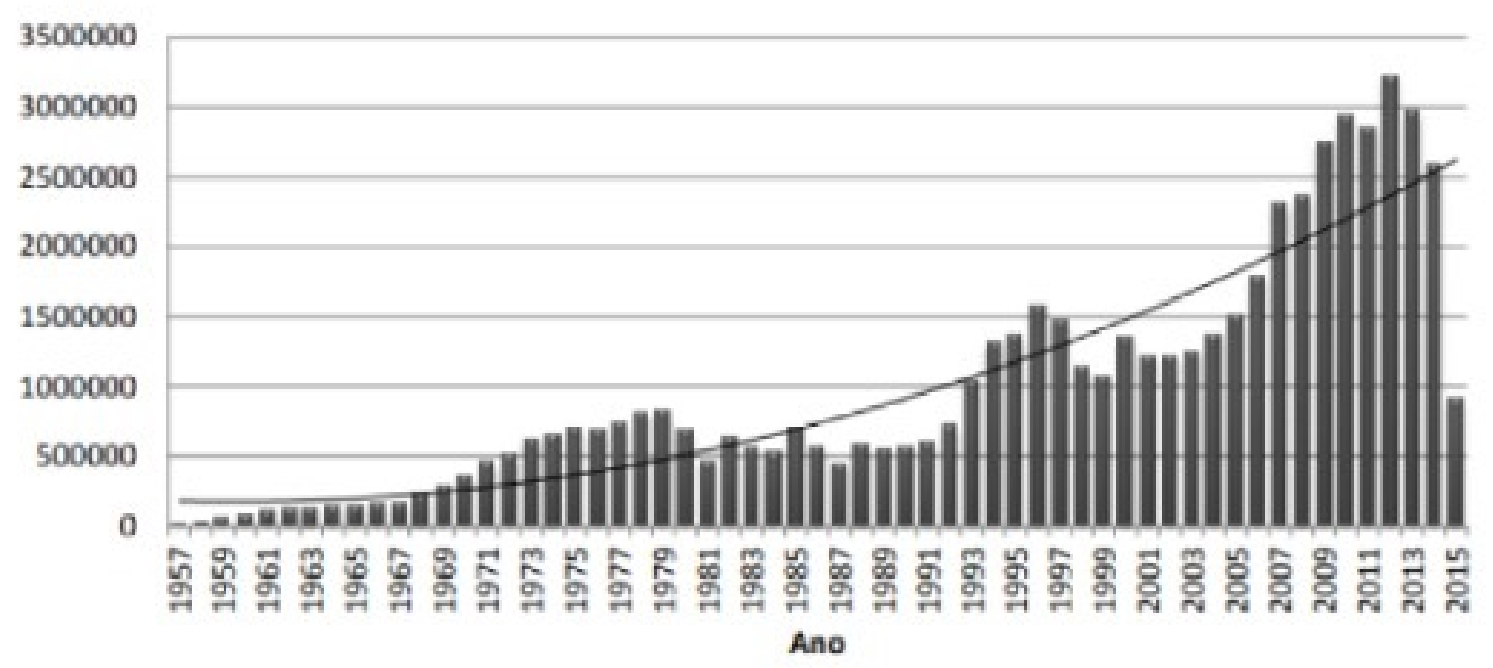

Fonte: Anfavea (2015)

A figura 1 demonstra que o Brasil foi tendo uma crescente constante em sua comercialização de veículos fabricados em território nacional, conforme as implementações e inovações dos materiais poliméricos foram chegando neste mercado.

Os impactos técnicos e econômicos ocorridos nos últimos 30 anos colocaram os polímeros em um patamar de destaque, tornando-se o polímero mais utilizado na indústria automotiva. Oferece inúmeras vantagens no âmbito da tecnologia, economia e meio ambiente. Atualmente, a indústria produz cerca de 4 milhões de toneladas de resina por ano e é responsável pelo abastecimento total do mercado brasileiro de commodities poliméricas. Suas vendas representam cerca de $1,5 \%$ do PIB do país.

Além das características mencionadas acima sobre os polímeros, o que mais impressiona os profissionais de projeto é a facilidade de transformação, especialmente a capacidade de obter diferentes formas, texturas e cores.

Segundo Lima (2006), o termo formação ou termo formagem pertence a um grupo de processos de conformação que utilizam temperatura e pressão de vácuo ou ar comprimido para moldagem de peças. Por fim, a extrusão é usada para produzir produtos contínuos como tubos e cabos revestidos. 
A abiplast (2016) relata que o uso dos plásticos nos veículos automotores oferece algumas vantagens como; segurança, flexibilidade, aumento da resistência à corrosão, possibilidade de desenhos mais modernos nas peças e, como mencionado, redução no consumo de combustível (por causa de baixa densidade dos materiais poliméricos), desse modo diminuindo a emissão de gases poluentes na atmosfera. Graças a essas características, os polímeros começaram a ser introduzidos nas mais variadas partes dos automóveis.

Temos como finalidade focar na indústria automobilística, onde o crescimento da utilização de polímeros ao longo dos anos é facilmente notado. De acordo com a Abiplast (2016) na década de 70, era usado em média 30 quilos de polímeros empregada por veículo, no final da década de 90, passou a representar cerca de 180 quilos e supõe-se que nos próximos cinco anos esse valor exceda os 200 quilos, segundo a Divisão de Plásticos do American ChemistryCouncil (ACC). A a dúvida neste momento, a partir do uso de plásticos na indústria automobilística, é sobre a disponibilidade de fornecimento de matérias-primas por parte da indústria de polímeros no Brasil.

Desde os primórdios da humanidade, a evolução humana está interligada à capacidade do homem em facilitar sua vida e aperfeiçoar técnicas. Com a invenção dos automóveis não foi diferente. O automóvel de três rodas criado no ano de 1885, pelo alemão Karl Benz foi o primeiro meio de transporte movido a um motor de gasolina. Em 1892, Henry Ford, cria seu primeiro carro na América do Norte, o espetacular Ford. Nesse tempo os carros eram pesados, não tão confortáveis e consumiam altas taxas de combustível.

Com o fim da primeira guerra, os produtores já existentes começaram a investir em carros mais econômicos, tomando uma grande proporção com o passar dos anos. Com a crise do petróleo entre 1973 e 1979 trouxeram a conscientização para o problema da falta de combustível e para a vulnerabilidade do uso indiscriminado de recursos naturais de fontes nãorenováveis. Estas crises podem ser consideradas como o momento crucial da tomada de posição quanto à construção de carros, a presença de peças plásticas nos automóveis foi fundamental para obter melhores padrões de segurança, economia de combustível e flexibilidade de manufatura. Em relação aos últimos anos no Brasil a troca de peças fabricadas com polímeros de alto desempenho por similares feitos com composições de polipropileno, mais baratas, fez com que as vendas desse polímero aumentassem, em 2001, em torno de $4 \%$, em relação a 2000 . 


\section{CONCLUSÃO}

Este artigo apresenta o relacionamento que existe entre a indústria de automóveis e os polímeros no Brasil. A ampla utilização do materiais poliméricosneste mercado, tem aumentado cada vez mais a sua importância, acima de tudo, proporcionando inúmeras vantagens, como economia, flexibilidade e segurança para o produto final.

Essa pesquisa é um método de levantamento de informações que tem o objetivo de comprovar as especialidades poliméricas e suas vantagens e desvantagens de serem utilizadas na indústria automobilística.

A evolução da utilização dos mesmos nos automóveis, oferece um produto com uma ótima qualidade final para o consumidor e consequentemente contribuindopara o meio ambiente.

\section{REFERÊNCIAS BIBLIOGRÁFICAS}

ABIPLAST (Associação brasileira da indústria do plástico). Perfil. São Paulo, SP: (2015)“Disponível em:

http://www.abiplast.org.br/wpcontent/uploads/2019/03/Perfil_-Abiplast_web2015.pdf." Acesso em 21 de maio de 2021.

ABIPLAST (Associação brasileira da indústria do plástico). Disponível em: https://www.repositorio.ufop.br/bitstream/123456789/11814/1/DISSERTA\%C3\%8 7\%C3\%83O_Degrada\%C3\%A7\%C3\%A3oEst\%C3\%A9ticaPolipropileno.pdf Acesso em 22 de maio de 2021.

$\begin{array}{llllll}\text { AGENCIA } & \text { BRASIL } & \text { SP } & - & \text { (2019). } & \text { Disponível }\end{array}$ em:https://agenciabrasil.ebc.com.br/economia/noticia/2019-08/venda-deveiculos-aumenta-121-no-primeiro-semestre-diz-anfavea. Acesso em 25 de maio de 2021.

CALLISTER Jr., William D. "Ciência e Engenharia dos Materiais - Uma Introdução." LTC - Livros Técnicos e Científicos S.A. Rio de Janeiro, 2002. 
CALLISTER, William D. "Ciência e Engenharia de Materiais: Uma Introdução" - $9^{\circ}$ EdiçãoLTC - Livros Técnicos e Científicos 2016, editora GEN.

CANEVAROLO Jr., Sebastião V. "Ciência dos Polímeros - Um Texto Básico para Tecnólogos e Engenheiros”. Artliber Editora. São Paulo, 2002.

DALMOLIN, Carla (2016). Disponível em:https://pt.slideshare.net/XavierAureliano/07-propriedades-termicas Acessoem 19 de maio de 2021.

DEYNA, A. Metalização de Polímeros Empregados no Setor Automotivo. Joinville:

Universidade Federal de Santa Catarina (UFSC), 2015. ISBN 9788578110796.

EEPA - (Encontro de Engenharia de produção agroindustrial.)(2015). Disponível em:.http://www.fecilcam .br/anais/ix_eepa/data/uploads/10-educacaoem-enge $\mathrm{n}$ h aria-de-producao/10-01.pdf. Acesso em 14 de maio de 2021.

ESTRATEGIA VESTIBULARES. (2019). Disponível em: https://blog.estrategiavestibulares.com.br/ quimica/polimeros/." Acesso em 18 de maio de 2021.

FOGAÇA, Jennifer. Manual da Química. O que são os polímeros?. Disponível em: <manualdaquimica.uol.com.br/química-organica/o-que-são-os-polimeros >. Acesso em 20 de Maio de 2021.

HEMAIS, Carlos. "Polímeros e a indústria automobilística." Disponível em http://www.scielo.br/scielo.php?script=sci_arttext\&pid=S010414282003000200008. Acesso em 10 de maio de 2021.

GOMES, Ana Paula Martins. Repositório institucional UFSC. Disponivelem : https://repositorio.ufsc.br/xmlui/handle/123456789/165313. Acesso em 21 de maio de 2021.

PLÁSTICO VIRTUAL. Disponível em: https://plasticovirtual.com.br/polimeroscompoem-60-das-pecas-usadas-nos-carros/. Acesso em 22 de Maio de 2021.

QUEVEDO, Renata Tomaz. Info Escola. Polímeros. Disponível em: < www.infoescola.com/quimica/polimeros/>. Acesso em 20 de Maio de 2021. 
QUEVEDO, Renata (2016). Disponível em: https://www.infoescola.com/quimica/propriedades-dos-polimeros/ . Acesso em 23 de maio de 2021

REDEMAT - (Rede temática em engenharias de materiais). (2019). Disponível em: https://www.repositorio.ufop.br/bitstream/123456789/11814/ 1/DISSERTA\%c3\%87\%c3\%830_Degrada\%c3\%a7\%c3\%a3oEst\%c3\%a9ticaPoli propileno.pdf. Acesso em 20 de maio de 2021.

SIMPLAST (Sindicato da indústria do material plástico do estado de minas gerais. 2018).Disponível em: http://simplast.com.br/servicos/fornecedores/. Acesso em 17 de maio de 2021. 